\title{
Enhancing Healthy Lifestyle in Professional Teachers' Training Programs in Universities of Russia
}

\author{
Viktoriya Levchenko \\ Department of Modern Languages and Professional \\ Communication \\ Samara National Research University \\ Samara, Russia \\ Levchenko_v2004@mail.ru
}

\author{
Alexander Levchenko \\ Department of Physical Education and Sport \\ Samara State University of Social Sciences and Education \\ Samara, Russia \\ Lavsport_67@mail.ru
}

\begin{abstract}
This article investigates a specific pedagogical approach to curricula design that encourages individuals to pursue a healthy lifestyle (HL). In the article the problem of HL focuses on education as a means of conveying knowledge about potential health threats or about certain forms of risky behavior. This paper focuses on four areas of health promotion on the postsecondary level: the curriculum, the social, the ecological and the community.

All four dimensions are considered an integral part of a comprehensive strategy for health promotion that embeds factual information on health-risk behavior into a context that is focused on everyday problem solving by the university population.

This article also presents the results of the study with more than 150 students of the Samara State University of Social Sciences and Education. The research indicates that a specific approach to curriculum design enhances regular exercises, and health checkups which reduces temporary inability to work and to study.
\end{abstract}

Keywords: healthy lifestyle (HL), curricula design, pedagogical approach, tertiary level

\section{INTRODUCTION}

An unhealthy lifestyle is a risk factor that is increasing among novice teachers. The objective of the study is to evaluate the efficacy of this intervention of enhancing healthy lifestyle (HL) in professional teachers' training programs.

Educational system of any country reflects the problems of any society in the historical period and guarantees realistic conditions for a developing society, forms new thinking, a new vision of the lifestyle. Human health (the state of complete physical, spiritual and social well-being) depends on lifestyle (up to $70 \%$ ), heredity $(15 \%)$, environment $(8-10 \%)$, medicine (8-10\%) [1]. An important input to decision-making and planning processes in healthy lifestyle of young people is a consistent and comparative description of professional teachers' training program in which a technology for healthenhancing activities could be implemented.

\section{LITERATURE REVIEW}

The World Health Organization defines health as "a state of physical, spiritual and social well-being, and not only the absence of disease and physical defects"'[2]

In general, we can talk about three types of health: the health of the physical, mental and public.

Physical health is a natural state of the body, conditioned by the normal functioning of all its organs and systems. If all organs and systems work well, then the entire human body (self-regulating system) is properly functioning and developing [3].

Mental health depends on the state of the brain, it is characterized by the level and quality of thinking, the development of attention and memory, the degree of emotional stability, the development of strong-willed qualities and can be defined as stress reactions, psychological wellbeing, and psychological distress, including depressive symptoms and anxiety [4].

Public health is determined by those moral principles that are the basis of a person's social life, i.e. Life in a particular human society. Distinctive features of the moral health of a person are, first of all, a conscious attitude to work, mastering the treasures of culture, active rejection of manners and habits that are contrary to the normal way of life [5]. A physically and mentally healthy person can be morally not a full-fledged person if he neglects the norms of morality. Therefore, social health is considered the highest measure of human health. A healthy and spiritually developed person is happy - he feels great, receives satisfaction from his work, strives for selfimprovement, reaching the unfading youth of spirit and inner beauty [6].

The analysis show that health is a complex phenomenon, understanding of it is the integral part of this investigation. 


\section{RESULTS}

According to a survey of the Samara State University of Social Sciences and Education (150 students), the notion of "physical education" is not associated with the notion of a "healthy lifestyle" and "health" in a significant number of the population $(26 \%)$. The majority of people $(43 \%)$ doubt not only of vital necessity, but also of the usefulness of physical education and sports. They do not consider that their health depends critically on themselves, their healthy way of life, which is based on physical culture. Many (23\%) associate the notion of "physical education" as a subject of study, while only $5 \%$ of respondents were confident in the direct dependence of their health on physical education.

Of the total number of people, $37.2 \%$ are practically healthy, $17.3 \%$ of them are first-year students, $14.6 \%$ are third-year students, $51.6 \%$ are fifth-year students.

$65.4 \%$ of students are sick with flu $-1-2$ times a year, the rest 3 or more times.

Only $25.1 \%$ of students have a good level of physical performance.

Thus, the students' acknowledgement of a HL is rather low. The vast majority of them underestimate the social value of health, a healthy lifestyle and physical education, low athletic activity, high morbidity, medium and low level of physical performance; $13 \%$ have an adverse reaction to the test with psycho-emotional stress; more than $80 \%$ of the students surveyed either do not have, or have insufficient knowledge and ideas about HL.

This survey showed that the importance of physical training is assessed in different ways. However, a number of researchers have proved experimentally that it is the physical culture that has a beneficial effect on the strengthening and preservation of human health and increases vitality.

We argue that a specific methodological approach for health-enhancing activities should be based on a HL model and play a role of a mechanism for implementing certain strategic concepts into practice. These strategic concepts come from the physical, mental and public types of the "health" and become the methodological basis of the HL model which is based on the concept of a person-centered education, the main idea of which is the individual development, goals achievement and self-development with a guiding value of health:

1. HL is a specific person (student) feature as a subject and object of his life and social status.

2. In the implementation of HL, a person (a student) stands in the unity of his biological and social principles.

3. The central idea of HL is the student's personalmotivational orientation toward the embodiment of his social, physical, intellectual or mental abilities.

4. HL is the most effective means and method of ensuring health, primary prevention of disease and meeting the vital need for health.
On the basis of HL model and according to the result of our research, the implemented system of enhancing healthy lifestyle in professional teachers' training programmes was determined by the following basic premises: individual typological hereditary factors; objective social conditions and socio-economic factors; specific living conditions in which the family-household and professional activities (educational activities) are carried out; personality-motivational factors determined by the world outlook and culture of a person (student) and the degree of their orientation toward health and HL.

The findings show the following shortcomings of higher education institutions in the HL management: the lack of HL traditions, the everyday nature of sports and other events, the low efficiency of using recreation areas and low quality of high school sports facilities. HL system is a combination of forms and methods of everyday cultural life of the individual. It includes norms, values, meanings of the activities regulated by them and its results, improving the adaptive capabilities of the organism, contributing to the full implementation of educational, labor, social and biological functions.

The basic indicators for the assessing the degree of enhancement of HL the Samara State University of Social Sciences and Education students (150 respondents) were:

1. value of health in the system of universal values;

2. physical culture in the value system of HL;

3. level of knowledge of HL.

It is established that out of the total number of interviewed students (150 people), $42.1 \%$ highly value health as a social value. In the healthy lifestyle system, the first grade of physical training as a basic component of HL is assigned to $12.7 \%$ of students. $17.5 \%$ of students have sufficient knowledge and ideas about healthy lifestyle. Regularly engaged in physical exercises $19.7 \%$ of students.

Enhancing HL requires more than focusing on risk factors of various diseases, alcoholism, smoking, lack of physical exercises, conflicts, although this is also of great health value. It is also important to cultivate a positive lifestyle. It is important to highlight and develop, actively strengthen the diverse trends that "work" for the enhancing HL in all aspects of life. For all basic psychological and physiological parameters, students aged 17-22 are ready for perception and development of HL, but many of them were (before the intervention) characterized by a low level of social preparedness, expressed in undervaluing health, and HL as social universal values, and values of physical culture as the fundamental component of HL.

\section{CONCLUSION}

Our study last for a year with the students of the Samara State University of Social Sciences and Education. The system of a specific curriculum design "36-36-36" based on the methodological approach for health-enhancing activities included 36 hours of interactive classes promoting health and 


\section{REFERENCES}

trainings and 36 hours of couching (with other students).

The indicators showed a positive dynamic in the following indicators:

- the level of knowledge about a healthy lifestyle (information-orientational criterion) $28 \%$;

- the desire to increase the level of knowledge about a healthy lifestyle and strengthen the health (needmotivational criterion) $34 \%$;

- assessment of the role of health in the system of universal values, physical culture in the system of values of healthy lifestyle and specific types of physical culture (value criterion) 64\%;

- factors that impede physical education, the overcoming of which indicates the manifestation of activity, perseverance and other will qualities of the individual in the development of healthy lifestyle (organizationalwilled criterion) $18 \%$;

- the level of mental and physical performance, health status and physical activity (activity-practical criterion) $24 \%$.

The results of the experiment, their analysis and discussion determined the trends in the efficiency of the specific approach to curriculum design "36-36-36" system for students at the Samara State University of Social Sciences and Education. Positive dynamics of students' knowledge and perceptions about healthy lifestyles and the healing role of physical culture, harmonization of physical development, the level of physical and mental health, the adaptive capabilities of individual body systems, the development of motor and other personal qualities, self-esteem of readiness to be healthy lifestyles among students, as well as regular independent classes students after completing a pedagogical experiment using aerobics - an indicator of the high success in the enhancing HL in professional teachers' training programmes.
[1] A. D. Lopez, C. D. Mathers, M. Ezzati, D. T. Jamison, and C. J. L. Murray, "Global and regional burden of disease and risk factors", Systematic analysis of population health data, 2001.

[2] World Health Organization", Overview of the World Health Report, Shaping the future Geneva, 2003 [Electronic resource]. Available at: https://www.who.int/whr/2003/en/overview_en.pdf.

[3] R. Bailey, K. Armour, D. Kirk, M. Jess, I. Pickup, R. Sandford, and BERA, "Physical Education and Sport Pedagogy Special Interest Group", The educational benefits claimed for physical education and school sport: an academic review, Research Papers in Education, 2009, 24(1), pp. 1-27. DOI: 10.1080/02671520701809817

[4] M. T. Ford, C. P.Cerasoli, J. A. Higgins, and A. L. Decesare, "Relationships between psychological, physical, and behavioural health and work performance: A review and meta-analysis", Work and stress, An International Journal of Work, Health \& Organizations, 2011, 25 (3), pp. $185-204$.

[5] D. A. Freedman, K. D. Bess, H. A. Tucker, D. L. Boyd, A. M. Tuchman, and K. A. Wallston, "Public Health Literacy Defined", American Journal of Preventive Medicine, 2009, pp. 446-451.

[6] G. L. Illin, "Scientific and pedagogical schools: a projective approach", Moscow, 1999.

[7] I. Kawachi and L.F. Berkman, "J Urban Health", 2001, 78, 458 p [Electronic resource]. Available at: https://doi.org/10.1093/jurban/78.3.458.

[8] J. K. Keay, N. Carse, and M. Jess, "Understanding teachers as complex professional learners", Professional Development in Education, 2019, 45 (1), pp. 125-137.

[9] A. Levchenko and V. Levchenko, "Exploring the structure of University corporate environment: Physical culture as an element of healthy lifestyle", State, Prospects and Development of Rescue, Physical Culture and Sports in the XXI century, 2015, 2, pp. 174-185.

[10] D. Penney, R. Brooker, P. Hay, and L. Gillespie, "Curriculum, pedagogy and assessment: three message systems of schooling and dimensions of quality physical education", Sport, Education and Society, 2009, 14 (4), pp. 421-442. DOI: 10.1080/13573320903217125

[11] J. Simmons and J. MacLean, "Physical education teachers' perceptions of factors that inhibit and facilitate the enactment of curriculum change in a high-stakes exam climate", Sport, Education and Society, 2018, 23 (2), pp. 186-202. DOI: 10.1080/13573322.2016.1155444

[12] M. Y. Vilensky, "Procedural characteristics of the formation of a healthy lifestyle of students", Physical culture is the basis of a healthy lifestyle, 1996, pp. 10-12.

[13] A. M. Voronov, "Pedagogical conditions for the formation of the physical culture of the future teacher in the process of his professional training in the university", $\mathrm{PhD}$ Thesis, Petrozavodsk, 2001. 